\title{
The impact of adding posterior instrumentation to transpsoas lateral fusion: a systematic review and meta-analysis
}

\author{
*Mohammed Ali Alvi, MBBS,, Redab Alkhataybeh, MBBS,,2 Waseem Wahood, MS, ,,2 \\ Panagiotis Kerezoudis, MD, MS, ${ }^{1,2}$ Sandy Goncalves, MS, ${ }^{1,2}$ M. Hassan Murad, MD, MPH, ${ }^{1-3}$ and \\ Mohamad Bydon, MD ${ }^{1,2}$
}

\begin{abstract}
${ }^{1}$ Mayo Clinic Neuro-Informatics Laboratory, ${ }^{2}$ Department of Neurologic Surgery, and ${ }^{3}$ Evidence-based Practice Center, Mayo Clinic, Rochester, Minnesota
\end{abstract}

\begin{abstract}
OBJECTIVE Transpsoas lateral interbody fusion is one of the lateral minimally invasive approaches for lumbar spine surgery. Most surgeons insert the interbody cage laterally and then insert pedicle or cortical screw and rod instrumentation posteriorly. However, standalone cages have also been used to avoid posterior instrumentation. To the best of the authors' knowledge, the literature on comparison of the two approaches is sparse.

METHODS The authors performed a systematic review and meta-analysis of the available literature on transpsoas lateral interbody fusion by an electronic search of the PubMed, EMBASE, and Scopus databases using PRISMA guidelines. They compared patients undergoing transpsoas standalone fusion (TP) with those undergoing transpsoas fusion with posterior instrumentation (TPP).
\end{abstract}

RESULTS A total of 28 studies with 1462 patients were included. Three hundred and seventy-four patients underwent TPP, and 956 patients underwent TP. The mean patient age ranged from 45.7 to 68 years in the TP group, and 50 to 67.7 years in the TPP group. The incidence of reoperation was found to be higher for TP $(0.08,95 \%$ confidence interval [CI] $0.04-0.11)$ compared to TPP $(0.03,95 \% \mathrm{Cl} 0.01-0.06 ; p=0.057)$. Similarly, the incidence of cage movement was found to be greater in TP $(0.18,95 \% \mathrm{Cl} 0.10-0.26)$ compared to TPP $(0.03,95 \% \mathrm{Cl} 0.00-0.05 ; \mathrm{p}<0.001)$. Oswestry Disability Index (ODI) and visual analog scale (VAS) scores and postoperative transient deficits were found to be comparable between the two groups.

CONCLUSIONS These results appear to suggest that addition of posterior instrumentation to transpsoas fusion is associated with decreased reoperations and cage movements. The results of previous systematic reviews and meta-analyses should be reevaluated in light of these results, which seem to suggest that higher reoperation and subsidence rates may be due to the use of the standalone technique.

https://thejns.org/doi/abs/10.3171/2018.7.SPINE18385

KEYWORDS transpsoas; XLIF; lumbar fusion; spine surgery; minimally invasive surgery

A CCORDING to a recent study, low-back pain is the second most common cause of disability in the US $^{9}$ and the reported 1-year incidence rate of any low-back pain ranges from $1.6 \%$ to $36 \% .^{17}$ The pathology is also associated with a huge economic burden, with some studies reporting a cost as high as $\$ 90.7$ billion. ${ }^{24}$ As such, there has been much advancement in both nonsurgical and surgical management of common pathologies leading to low-back pain. Among surgical modalities, minimally in- vasive techniques have recently been increasingly adopted by neurosurgeons. ${ }^{21}$

A commonly used surgical technique in treating pathologies of the spine is transpsoas lateral lumbar interbody fusion. The technique was first described by Ozgur et al. in 2006 and has since been endorsed by many spine surgeons. ${ }^{36}$ There have been several studies since its first description highlighting the improved outcomes, ease of access, and lower/comparable complications when com-

ABBREVIATIONS GRADE = Grading of Recommendations Assessment, Development and Evaluation; ODI = Oswestry Disability Index; PRISMA = Preferred Reporting Items for Systematic Reviews and Meta-Analyses; TP = standalone transpsoas lateral lumbar interbody fusion; TPP = transpsoas lateral lumbar interbody fusion with posterior instrumentation; VAS = visual analog scale.

SUBMITTED March 30, 2018. ACCEPTED July 10, 2018.

INCLUDE WHEN CITING Published online November 2, 2018; DOI: 10.3171/2018.7.SPINE18385.

${ }^{*}$ M.A.A. and R.A. share first authorship of this work. 
TABLE 1. GRADE assessment of quality of evidence

\begin{tabular}{|c|c|c|c|c|c|}
\hline Outcome & No. of Studies & No. of Pts & Inconsistency & Relative Effect (95\% Cl) & Confidence in Effect Estimates (GRADE) \\
\hline \multicolumn{6}{|l|}{ TP } \\
\hline VAS (leg) at $1 \mathrm{yr}$ & 7 & 366 & Not serious & $-3.83(-4.15,-3.51)$ & Low \\
\hline ODI at $1 \mathrm{yr}$ & 5 & 175 & Serious & $-28.9(-31.9,-25.9)$ & Very low \\
\hline Fusion rate & 9 & 452 & Not serious & $0.92(0.90,0.95)$ & Very low \\
\hline Length of stay & 5 & 171 & Serious & $1.21(1.11,1.31)$ & Very low \\
\hline Op time & 8 & 415 & Not serious & $81.3(79.3,83.4)$ & Low \\
\hline Cage movement & 11 & 565 & Serious & $0.18(0.10,0.26)$ & Low \\
\hline Reops & 13 & 926 & Serious & $0.08(0.04,0.11)$ & Low \\
\hline Transient deficits & 7 & 391 & Serious & $0.29(0.10,0.47)$ & Very low \\
\hline \multicolumn{6}{|l|}{ TPP } \\
\hline VAS (leg) at $1 \mathrm{yr}$ & 7 & 198 & Not serious & $-3.62(-3.68,-3.56)$ & Low \\
\hline ODI at $1 \mathrm{yr}$ & 6 & 206 & Serious & $-21.1(-21.5,-20.8)$ & Very low \\
\hline Length of stay & 9 & 235 & Not serious & $4.20(3.73,4.67)$ & Low \\
\hline Op time & 10 & 319 & Not serious & $86.1(84.2,88.0)$ & Low \\
\hline Fusion rate & 6 & 154 & Not serious & $0.93(0.90,0.97)$ & Very low \\
\hline Cage movement & 5 & 160 & Not serious & $0.03(0.00,0.05)$ & Very low \\
\hline Reops & 8 & 203 & Serious & $0.03(0.01,0.06)$ & Very low \\
\hline Transient deficits & 12 & 284 & Serious & $0.24(0.14,0.34)$ & Very low \\
\hline
\end{tabular}

Pts = patients.

"Indirectness" was serious for all variables, and "imprecision" and "other consideration" were not serious for all variables.

pared to other conventional approaches. ${ }^{1,7,8,12,13,18,19,27,28}$ One of the prime objectives is to minimize collateral tissue and muscle trauma while ensuring optimum clinical results. Hence, the standalone transpsoas lateral lumbar interbody fusion was described, in which the disc space is approached from a lateral trajectory through the psoas muscle and an interbody cage is placed. In addition to the lateral cage placement, posterior fixation is also applied using pedicle or cortical screw-rod instrumentation. Some surgeons employ a standalone technique where the cage is placed without posterior instrumentation. ${ }^{37}$ Several studies and systematic reviews have compared the lateral fusion technique to other conventional approaches as well as other minimally invasive techniques, such as anterior-topsoas lumbar interbody fusion. . $, 20,29,45$ However, to the best of our knowledge, there is not much literature on comparison of clinical and operative outcomes between standalone transpsoas lateral lumbar interbody fusion and transpsoas lateral lumbar interbody fusion with posterior fixation. Therefore, in this paper we present a systematic review and meta-analysis of clinical and operative outcomes between standalone transpsoas lateral lumbar interbody fusion (TP) and transpsoas lateral lumbar interbody fusion with posterior instrumentation (TPP).

\section{Methods}

This systematic review is reported according to the PRISMA (Preferred Reporting Items for Systematic Reviews and Meta-Analyses) guidelines. ${ }^{30}$

\section{Search Strategy}

An electronic search of the PubMed, EMBASE, and
Scopus databases was performed to identify studies on transpsoas lateral interbody fusion using PRISMA guidelines. Our search method was as follows: 1) ((stand* adj alone) or standalone).tw. AND lumbar AND (fusion.mp or (llif or xlif or elif or dlif or olif or alif or mis-dlif or plif or tlif or lateral fusion or anterolateral fusion).tw); 2) Cage*1. tw AND (fusion*.mp or (llif or xlif or elif or dlif or olif or alif or mis-dlif or plif or tlif).tw.) AND (lumbar and posterior*).tw; and 3) (1 or 2) and (Exp Treatment outcome/ or outcome*1.mp).

The last date searched was July 27, 2017. Two authors performed an individual literature search (R.A. and M.A.A.). The initial result yielded 909 articles. Articles were grouped according to the type of fusion as follows: TP or TPP.

\section{Study Selection Criteria}

Only those articles were included in which: 1) some form of the surgery of interest, i.e., transpsoas lateral interbody fusion, was employed; 2) a complete description of the technique was available; 3 ) full-text was available; and 4) at least one of the outcomes was studied. The outcomes were: 1) visual analog scale (VAS) score; 2) Oswestry Disability Index (ODI); 3) length of stay; 4) fusion rate; 5) complication rate, particularly subsidence; 6) readmissions; 7) reoperations; 8) transient neurological deficits; 9) permanent neurological deficits; 10) operative time; and 11) estimated blood loss. Included articles were those that were available in English and had full-text available. If the articles included a comparison of our surgical technique of interest (TP or TPP) with some other technique, we only included the data for the TP or TPP group. Articles were excluded if 1) they included fewer than 8 patients; 2) they 
TABLE 2. Assessment of the quality of included studies according to the Newcastle-Ottawa Quality Assessment Scale

\begin{tabular}{|c|c|c|c|c|c|c|}
\hline \multirow[b]{2}{*}{ Authors \& Year } & \multicolumn{6}{|c|}{ Quality Assessment Criteria } \\
\hline & $\begin{array}{l}\text { Representativeness } \\
\text { of Cohort }\end{array}$ & $\begin{array}{l}\text { Ascertainment } \\
\text { of Exposure }\end{array}$ & $\begin{array}{l}\text { Outcome } \\
\text { of Interest }\end{array}$ & $\begin{array}{l}\text { Assessment } \\
\text { of Outcome }\end{array}$ & $\begin{array}{c}\text { Adequate } \\
\text { Duration of FU }\end{array}$ & $\begin{array}{c}\text { Adequate FU } \\
\text { of Cohort }\end{array}$ \\
\hline \multicolumn{7}{|l|}{ TP } \\
\hline Ahmadian et al., 2015 & Yes & Yes & Yes & $-^{*}$ & Yes & Yes \\
\hline Bouthors et al., 2015 & Yes & Yes & Yes & Yes & Yes & Yes \\
\hline Essig et al., 2014 & Yes & Yes & Yes & Yes & Yes & Yes \\
\hline Heini et al., 2013 & Yes & Yes & $-\dagger$ & Yes & Yes & Yes \\
\hline Marchi et al., 2012 & Yes & Yes & Yes & Yes & Yes & Yes \\
\hline Marchi et al., 2013 & Yes & Yes & Yes & Yes & Yes & Yes \\
\hline Nemani et al., 2014 & Yes & Yes & Yes & Yes & Yes & Yes \\
\hline Oliveira et al., $2010^{34}$ & Yes & Yes & Yes & Yes & Yes & Yes \\
\hline Oliveira et al., $2010^{33}$ & Yes & Yes & Yes & Yes & - & - \\
\hline Oliveria et al., $2010^{32}$ & Yes & Yes & Yes & Yes & Yes & Yes \\
\hline Pimenta et al., 2013 & Yes & Yes & Yes & Yes & Yes & Yes \\
\hline Tempel et al., 2015 & Yes & Yes & Yes & Yes & Yes & Yes \\
\hline \multicolumn{7}{|l|}{ TPP } \\
\hline Abbasi \& Abbasi, 2017 & Yes & Yes & Yes & Yes & Yes & Yes \\
\hline Alimi et al., 2018 & Yes & Yes & Yes & Yes & - & Yes \\
\hline Anand et al., 2008 & Yes & Yes & Yes & Yes & Yes & Yes \\
\hline Anand et al., 2010 & Yes & Yes & Yes & Yes & - & Yes \\
\hline Castellvi et al., 2014 & Yes & Yes & Yes & Yes & Yes & Yes \\
\hline Drazin et al., 2015 & Yes & Yes & Yes & Yes & Yes & Yes \\
\hline Jin et al., 2018 & Yes & Yes & Yes & Yes & Yes & Yes \\
\hline Knight et al., 2009 & Yes & Yes & Yes & Yes & Yes & Yes \\
\hline McAfee et al., 2013 & Yes & Yes & Yes & Yes & - & Yes \\
\hline Tessitore et al., 2017 & Yes & Yes & Yes & Yes & - & Yes \\
\hline Tormenti et al., 2010 & Yes & Yes & $-\ddagger$ & Yes & Yes & Yes \\
\hline Waddell et al., 2014 & Yes & Yes & Yes & Yes & Yes & Yes \\
\hline Wang \& Mummaneni, 2010 & Yes & Yes & Yes & Yes & Yes & Yes \\
\hline TP vs TPP & & & & & - & \\
\hline Kim et al., 2012 & Yes & Yes & Yes & Yes & - & - \\
\hline Malham et al., 2017 & Yes & Yes & $-\S$ & Yes & Yes & Yes \\
\hline Youssef et al., 2010 & Yes & Yes & Yes & Yes & Yes & Yes \\
\hline \multicolumn{7}{|c|}{$\begin{array}{l}\text { FU = follow-up. } \\
\text { * No use of CT or medical records, only hospital length of stay, fusion rates, neurological complications, integrity of construct, and clinical } \\
\text { outcome questionnaires. } \\
\text { † Twenty patients had a revision surgery or vertebroplasty after intervention. } \\
\text { † Patients had previous lumbar surgeries and comorbidities. } \\
\S \text { Of the } 21 \text { patients, } 6 \text { had previous lumbar surgeries, } 2 \text { patients currently smoke. }\end{array}$} \\
\hline
\end{tabular}

were case reports, case series, or cadaveric studies; 3 ) they did not study outcomes of interest; 4) the study did not differentiate between standalone and posterior instrumentation in their results; and 5) they were editorials or abstracts.

\section{Outcomes}

Primary outcomes were fusion rate, reoperation rate, and incidence of subsidence. Other analyses included patient-reported outcomes, such as VAS score and ODI, and other complications, which included transient and permanent neurological deficits. All complication rates, hematomas, vertebral fractures, vascular complications, bowel perforations, and estimated blood loss were excluded from analyses due to inconsistent reporting. Missing data were imputed using validated methods. ${ }^{16}$

\section{Data Extraction and Analysis}

Two authors (R.A. and W.W.) reviewed the included studies and abstracted the following variables: 1) patient demographics, including age, sex, ethnicity, and BMI; 2) operative outcomes, including estimated blood loss and operative time; 3) clinical outcomes, including length of stay and fusion rate along with method of reporting fusion; and 4) complications, including all complication rates, hema- 


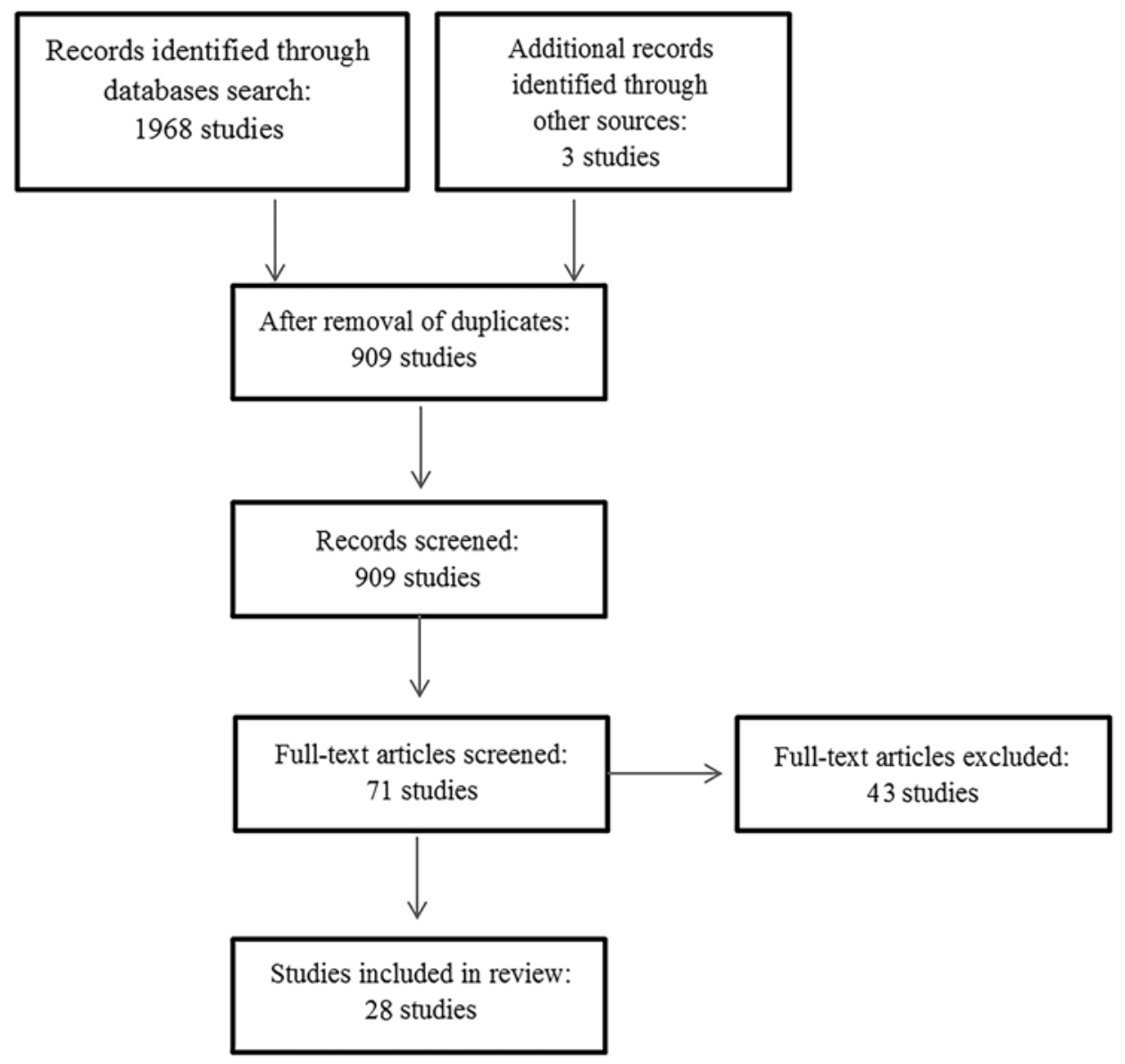

FIG. 1. Flow diagram depicting the literature review, search strategy, and selection process.

tomas, vertebral fractures, transient and permanent neurological deficits, vascular complications, bowel perforations, subsidence, readmissions, and reoperations. Meta-analysis was performed for eight variables: VAS scores, ODI, number of reoperations, cage movements, fusion rates, transient deficits, operative time, and length of hospital stay. Meta-regression was used for the continuous variables: VAS scores, ODI, operative time, and length of hospital stay. A random-effects model (DerSimonian and Laird approach ${ }^{10}$ ) was used to account for the high variability of the populations between single-institution studies. A t-test of weighted averages was used to compare estimated blood loss. Primary outcomes were reported as incidence for categorical values and means for continuous data. A p value $<0.05$ was considered significant. All analyses were performed using Stata (version 14, StataCorp LP).

\section{Methodological Quality and Quality of Evidence}

Risk of bias of each study was assessed using the modified Newcastle Ottawa Scale ${ }^{44}$ focusing on cohort selection and removing comparability. The quality of evidence (i.e., certainty in the estimate of effect) was assessed using the Grading of Recommendations Assessment, Development and Evaluation (GRADE) approach (Table 1). ${ }^{14}$ Given the methodology of the current systematic review and metaanalysis, assessment of outcome was found to be the best indicator of the quality of the studies. We modified the assessment criteria by removing some components that were not suitable for indirect comparisons. The assessment can be found in Table 2 .

\section{Results \\ Description of Studies}

After applying the exclusion criteria to 909 studies retrieved from the initial search, 28 studies were included in the meta-analysis that consisted of a total of 1462 eligible patients. Figure 1 outlines the study flow chart. Thirteen studies compared TPP with other techniques, involving a total of 374 patients and 759 treated levels. . $^{1,3,4,5,8,11,19,23}$, 28,40-43 Twelve studies compared TP to some other fusion technique, including a total of 956 patients and 1733 treated levels. ${ }^{2,7,12,15,26,27,31-34,38,39}$ Three studies compared standalone TP with TPP, involving a total of 132 patients and 211 levels treated. ${ }^{22,25,46}$

Mean age ranged from 45.7 to 68 years in the TP group, and 50 to 67.7 years in the TPP group. Mean BMI ranged from 26.7 to 31.0 for the TPP group, and 25.0 to 27.5 for the TP group. The proportion of females ranged from $53.3 \%$ to $76.38 \%$ for the TP group, and $33.33 \%$ to $76.1 \%$ for the TPP group. The mean number of levels of fusion was 1.74 levels per patient for the TP group, compared with 1.38 
TABLE 3. Demographics and characteristics of included studies

\begin{tabular}{|c|c|c|c|c|c|c|c|c|c|}
\hline Authors \& Year & Country & Study Design & $\begin{array}{c}\text { Sample } \\
\text { Size }\end{array}$ & $\begin{array}{l}\text { No. of } \\
\text { Levels }\end{array}$ & $\begin{array}{c}\text { Females } \\
(\%)\end{array}$ & $\begin{array}{l}\text { Mean } \\
\text { Age } \\
\text { (yrs) }\end{array}$ & $\begin{array}{c}\text { Mean } \\
\text { BMl } \\
\left(\mathrm{kg} / \mathrm{m}^{2}\right)\end{array}$ & Mean FU & $\begin{array}{c}\text { Included } \\
\text { Deformity } \\
\text { Pts? }\end{array}$ \\
\hline \multicolumn{10}{|l|}{ TP } \\
\hline Ahmadian et al., 2015 & USA \& Australia & Retrospective & 59 & 96 & 61 & 59 & NA & $14.6 \mathrm{mos}$ & Yes \\
\hline Bouthors et al., 2015 & France & Retrospective & 60 & 74 & NA & NA & NA & 19 mos & Yes \\
\hline Essig et al., 2014 & USA & Retrospective & 55 & 115 & 72.7 & NA & NA & $67.5 \mathrm{mos}$ & Yes \\
\hline Heini et al., 2013 & Switzerland & Prospective (observational) & 95 & 179 & 73.68 & 68 & NA & 12 mos & Yes \\
\hline Marchi et al., 2012 & Brazil & Prospective (observational) & 52 & 52 & 73.1 & 67.6 & 27.4 & $24 \mathrm{mos}$ & No \\
\hline Marchi et al., 2013 & Brazil & Prospective (observational) & 74 & 98 & 64.86 & 57 & 25.0 & $12 \mathrm{mos}$ & No \\
\hline Nemani et al., 2014 & Austria & Retrospective & 117 & 239 & 70.9 & 63.6 & 27.5 & $15.6 \mathrm{mos}$ & Yes \\
\hline Oliveira et al., $2010^{33}$ & Brazil & Prospective (observational) & 21 & 43 & 66.67 & 67.6 & NA & NA & No \\
\hline Oliveria et al., $2010^{32}$ & Brazil, USA & Prospective (observational) & 15 & 15 & 53.3 & 45.7 & NA & 2 yrs & No \\
\hline Oliveira et al., $2010^{34}$ & Brazil & Prospective (RCT) & 43 & 77 & NA & 66.3 & 25.6 & $12 \mathrm{mos}$ & No \\
\hline Pimenta et al., 2013 & Brazil & Retrospective & 30 & 30 & 60 & 47.4 & NA & $36 \mathrm{mos}$ & No \\
\hline Tempel et al., 2015 & USA & Retrospective & 335 & 715 & NA & NA & NA & NA & Yes \\
\hline \multicolumn{10}{|l|}{ TPP } \\
\hline Abbasi \& Abbasi, 2017 & USA & Prospective (observational) & 9 & 15 & 33.3 & 50 & 31.0 & 12 mos & No \\
\hline Alimi et al., 2018 & USA & Retrospective & 84 & 145 & 61.9 & 64.6 & NA & $17.7 \mathrm{mos}$ & Yes \\
\hline Anand et al., 2008 & USA & Prospective (observational) & 12 & 44 & 41.6 & 72.8 & NA & 75.5 days & Yes \\
\hline Anand et al., 2010 & USA & Retrospective & 28 & 99 & NA & 67.7 & NA & 22 mos & Yes \\
\hline Castellvi et al., 2014 & USA & Retrospective & 44 & 117 & 47.73 & 66 & 29.4 & 12 mos & Yes \\
\hline Drazin et al., 2015 & USA & Retrospective & 20 & NA & 45 & 54.5 & 26.7 & $9 \mathrm{mos}$ & No \\
\hline Jin et al., 2018 & Korea & Retrospective & 22 & 22 & 59 & 66.9 & NA & NA & Yes \\
\hline Knight et al., 2009 & USA & Retrospective & 58 & 79 & 74.13 & 61 & NA & 15 mos & No \\
\hline McAfee et al., 2013 & USA & Retrospective & 25 & 78 & 65.9 & NA & NA & $24.6 \mathrm{mos}$ & Yes \\
\hline Tessitore et al., 2017 & Switzerland & Retrospective & 20 & 22 & 50 & 67.5 & NA & $9.8 \mathrm{mos}$ & No \\
\hline Tormenti et al., 2010 & USA & Retrospective & 8 & 23 & NA & 60 & NA & $10.5 \mathrm{mos}$ & Yes \\
\hline Waddell et al., 2014 & USA & Retrospective & 21 & 54 & 76.1 & 66.6 & NA & 12 mos & Yes \\
\hline Wang \& Mummaneni, 2010 & USA & Retrospective & 23 & 61 & 74 & 64.4 & NA & $13.4 \mathrm{mos}$ & Yes \\
\hline \multicolumn{10}{|l|}{ TP vs TPP } \\
\hline Kim et al., 2012 & Korea & Retrospective & $8(4+4)$ & 20 & 87.5 & 65.8 & NA & $3 \mathrm{mos}$ & Yes \\
\hline Malham et al., 2017 & Australia & Prospective (observational) & $40(19+21)$ & 54 & 70 & 64 & 26.9 & $12 \mathrm{mos}$ & Yes \\
\hline Youssef et al., 2010 & USA & Retrospective & $84(38+46)$ & 137 & NA & NA & NA & $12 \mathrm{mos}$ & Yes \\
\hline
\end{tabular}

$\mathrm{NA}=$ not available; $\mathrm{RCT}=$ randomized controlled trial.

levels per patient for the TPP group. Patient demographics and characteristics of included studies are shown in Table 3 . Various outcomes have been summarized in Supplemental Tables 1-3.

\section{Reoperations}

For the TP group, 13 studies (926 patients) reported data on reoperations. For the TPP group, 8 studies (203 patients) included data on reoperation. Mean incidence of reoperation was found to be marginally greater in the TP group $(0.08,95 \%$ CI $0.04-0.11)$ compared to the TPP group $(0.03,95 \% \mathrm{CI} 0.01-0.06 ; \mathrm{p}=0.057)$. These results are further assessed as forest plots (Fig. 2).

\section{Cage Movement}

Eleven studies (565 patients) reported data on cage movement (which includes subsidence and migration) for the TP group. As for the TPP group, 5 studies (160 patients) reported data on this outcome. The mean incidence of cage movement was found to be greater in the TP group $(0.18,95 \%$ CI $0.10-0.26)$ compared to the TPP group $(0.03,95 \%$ CI $0.00-0.05 ; \mathrm{p}<0.001)$. These results are also further assessed as forest plots (Fig. 3).

\section{Fusion Rate}

Nine studies (452 patients) reported data on fusion rate for the TP group, while 6 studies (154 patients) reported data on fusion rate for the TPP group. Of these 15 studies, 2 reported data on this outcome for both groups. Five of 9 studies in the TP group reported fusion by $\mathrm{CT}$ at 1 year, 2 by $\mathrm{CT}$ and radiography at 1 year, 1 by CT and radiography at last follow-up, and 1 by CT at last follow-up. Five 


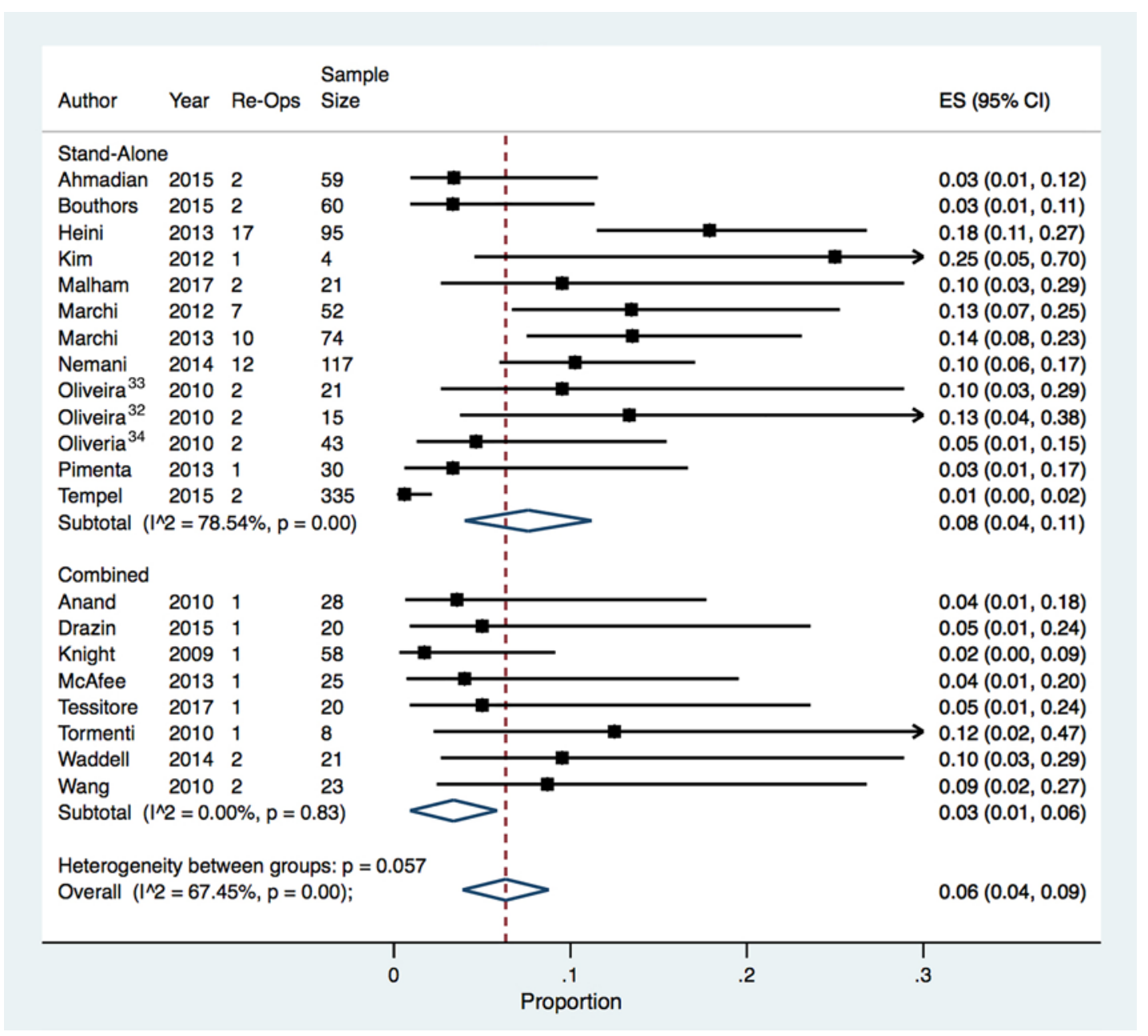

FIG. 2. Forest plot of reoperations for TP and TPP groups. ES = effect size. Figure is available in color online only.

of 6 studies in the TPP group reported fusion by CT at 1 year, and 1 study reported fusion by $\mathrm{CT}$ at last follow-up. The mean incidence rate of fusion was found to be similar between the two groups with a rate of $0.92(95 \% \mathrm{CI}$ 0.90-0.95) for the TP group and 0.93 (95\% CI 0.90-0.97) for the TPP group $(\mathrm{p}=0.650)$. These results are further assessed as forest plots (Fig. 4).

\section{Transient Deficits}

Transient deficits included transient numbness or transient weakness of the thigh. For the TP group, 7 studies (391 patients) reported data on transient deficits. For the TPP group, 12 studies (284 patients) included data on this complication. The mean incidence of transient deficits was found to be similar between the two groups with an incidence rate of 0.29 (95\% CI $0.10-0.47)$ for the TP group and 0.24 (95\% CI 0.14-0.34) for the TPP group (p $=0.654)$. These results are further assessed as forest plots (Fig. 5).

\section{VAS Score}

Seven studies (366 patients) reported radicular leg pain VAS scores after a 12-month follow-up for the TP group. Seven studies (198 patients) reported VAS scores for the TPP group. Of these 14 studies, 1 reported VAS scores for both groups. There was no statistically significant difference in VAS scores $(p=0.253)$ between the two groups.

\section{ODI Scale}

Five studies (175 patients) reported ODI scores for the TP group, while 6 studies (206 patients) reported ODI scores for the TPP group. Of these 11 studies, 1 reported ODI scores for both groups. There was no statistically significant difference in ODI scores $(\mathrm{p}=0.071)$ between the two groups.

\section{Length of Hospital Stay}

Five studies (171 patients) reported length of stay for the TP group, while 9 studies (235 patients) reported length of stay for the TPP group. Of these 14 studies, 1 reported length of stay for both groups. There was a statistically significant difference in length of hospital stay $(p=0.02)$ between the two groups. 


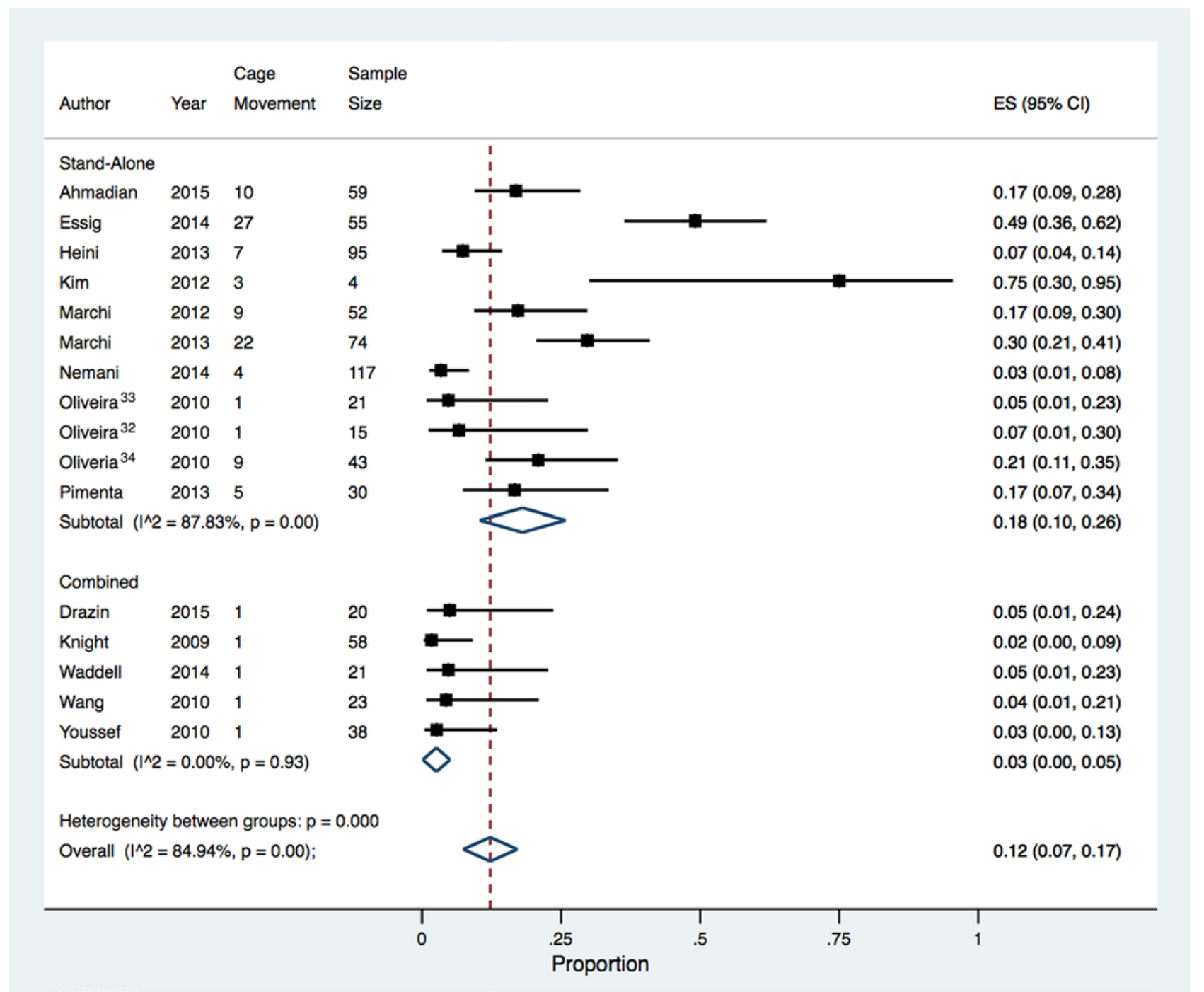

FIG. 3. Forest plot of cage movement for TP and TPP groups. Figure is available in color online only.

\section{Operative Time}

Eight studies (415 patients) reported operative time for the TP group, while 10 studies (319 patients) reported operative time for the TPP group. Of these 18 studies, 1 reported operative time for both groups. There was a statistically significant difference in operative times $(p=0.007)$ between the two groups

\section{Estimated Blood Loss}

Six studies (354 patients) reported estimated blood loss for the TP group, while 10 studies (319 patients) reported this variable for the TPP group. There was no statistically significant difference in estimated blood loss $(p=0.335)$ between the two groups.

\section{Quality of Evidence}

The overall quality of evidence for most outcomes obtained through this meta-analysis is low (Table 1). Also, as evident from Table 2, we were unable to demonstrate the selection of an unexposed cohort (control group) and comparability of cohorts in these studies as part of the Newcastle-Ottawa assessment. Hence they were removed from the assessment criteria and might have introduced measurement bias in our analysis.

\section{Discussion}

Minimally invasive techniques are increasingly being considered for lumbar interbody fusion. Transpsoas lateral fusion is one of the most commonly employed techniques. This is either performed as a standalone approach or combined with additional posterior instrumentation. Only 3 studies compared the standalone technique to posterior fixation and were included in these analyses.

Studies that compared these two approaches directly reported higher blood loss, longer operative times, and a longer length of stay for the combined approach. ${ }^{22,25,46}$ These results were consistent with our findings. One pos- 


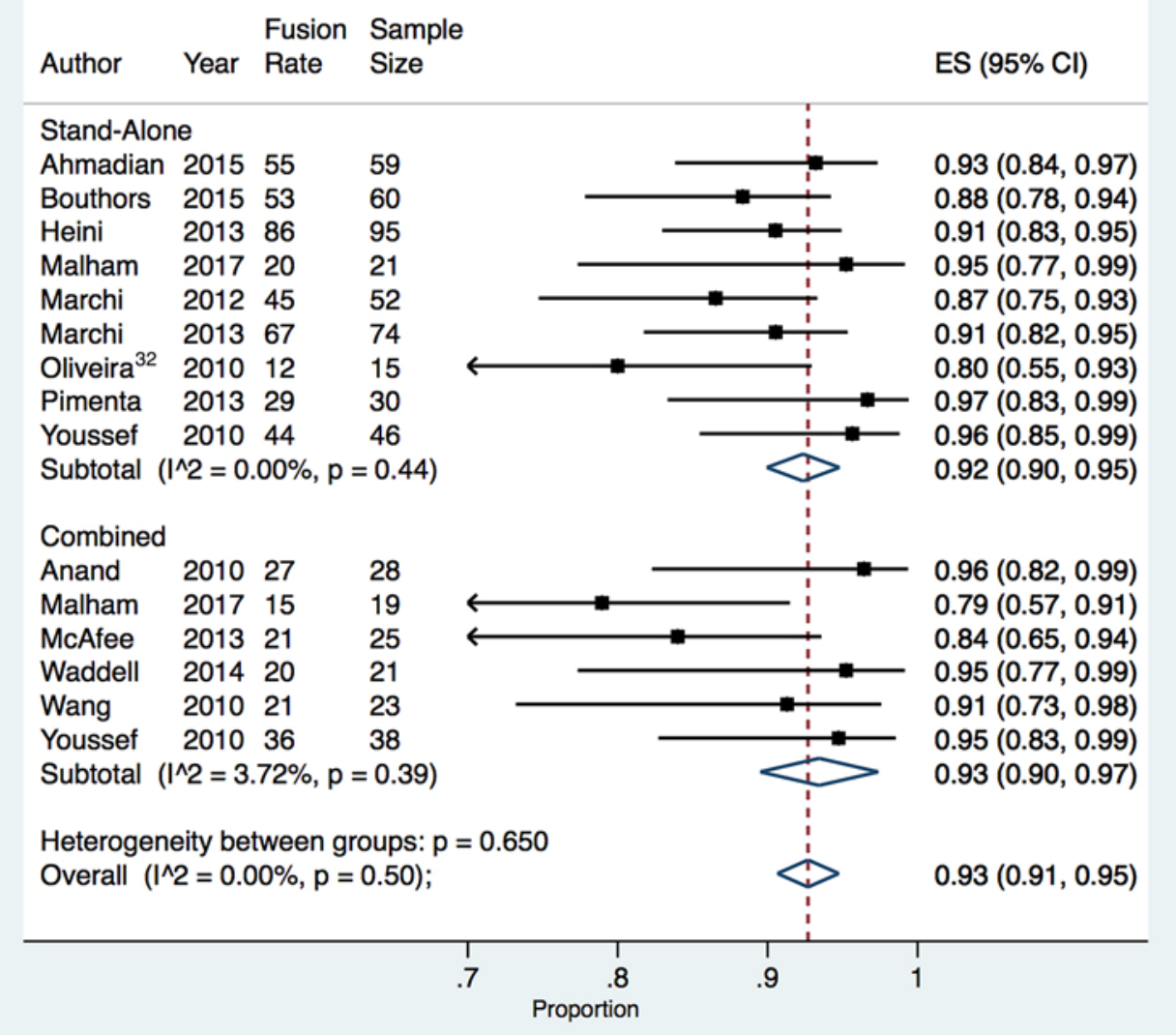

FIG. 4. Forest plot of fusion rates for TP and TPP groups. Figure is available in color online only.

sibility for this difference between the approaches is that the combined approach includes pedicle screws, requiring additional surgery. On the other hand, the standalone approach is much more cost-effective. ${ }^{15}$ Most of the studies that were excluded from the meta-analysis were due to nondelineated results. However, their findings were compared to our analysis. Ozgur et al. ${ }^{35}$ reported VAS and ODI scores for 62 patients who underwent TP or TPP. The mean VAS score decreased by 2.1 after a 1-year follow up, in contrast to our calculated mean VAS score improvement of 3.62 for both treatment groups together (Table 1). Mean ODI score decreased by 21, compared to our calculated mean ODI improvement of 24.3 after 1-year followup (Table 1). Joseph et al. ${ }^{20}$ in 2015 conducted a systematic review and meta-analysis to compare outcomes between minimally invasive transforaminal lumbar interbody fusion and lateral fusion. They reported a pooled subsidence rate of $10.84 \%$, which is similar to the rate of $12 \%$ that we found for both groups combined. However, it is interesting to note the stark difference between the subsidence rate of standalone TP (18\%) and TPP (3\%), which seems to suggest that the high rate of subsidence reported in the literature may be because of the standalone (TP) approach.

Patients with deformity may represent a clinically heterogeneous population, which may influence the outcomes that were studied in the current review. However, we found that among studies on combined cage and posterior fixation, 13 of 16 included patients with deformity. Of the studies that did not include deformity $(n=3)$, only 1 study reported subsidence. Similarly, among 15 studies on TP, 6 included patients with deformity. Therefore, a sensitivity analysis could not be performed to isolate the effect of deformity on subsidence and fusion rate.

The reoperation rate reported by the previous systematic review was $3.74 \%^{20}$ compared to $6 \%$ found in this current paper for both approaches combined. Again, the higher rate of reoperation may be attributed more to the standalone approach (8\%) than the combined approach $(3 \%)$ as reported in this paper.

These results appear to suggest that while adding posterior instrumentation to lateral fusion might result in slightly less pain relief, it significantly reduces the risk of subsidence and reoperation. It is worth reporting here that none of the devices being currently utilized for lateral fusion have FDA approval for standalone use. This means that the use of these device sets as a standalone approach may be considered off-label.

\section{Limitations}

The limitations of this study, first and foremost, are akin to those of any indirect systematic review, meaning that most of these studies analyzed either approach, except for 3 studies that directly compared the two approaches..$^{22,25,46}$ 


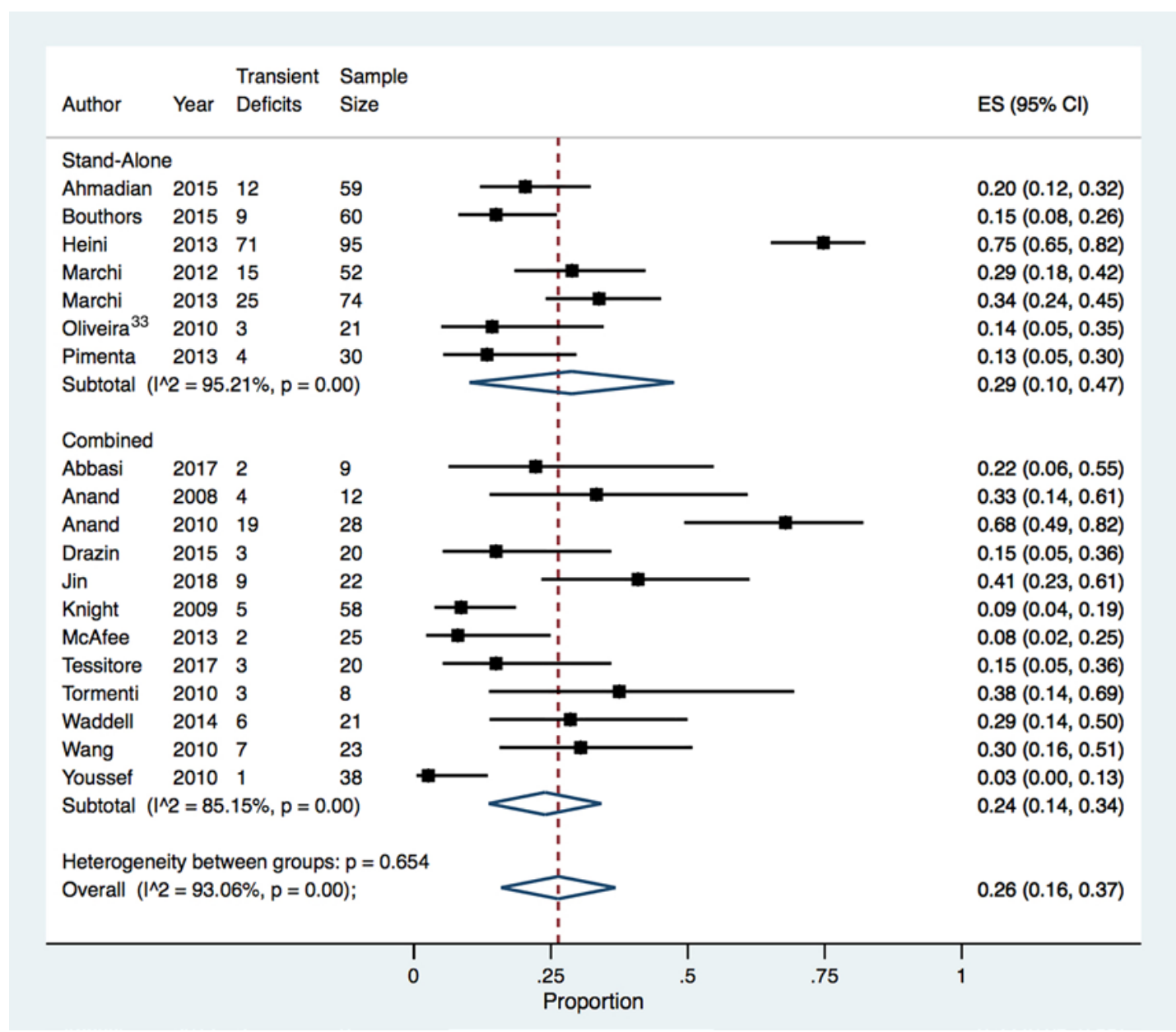

FIG. 5. Forest plot of transient deficits for TP and TPP groups. Figure is available in color online only.

Indirect comparisons do not allow robust comparisons and thus the level of evidence obtained is low. Moreover, all of these studies were retrospective in nature. Furthermore, some outcomes, such as blood loss, could not be fully analyzed due to missing or inconsistent data. There was also a lack of reporting of basic patient characteristics (such as BMI and comorbidities) in most studies that could have influenced some of the outcomes analyzed. Nonetheless, we have reported mean BMI for studies that have included them. In addition, some studies compared standard and wide cages, which may have created some bias in the results. ${ }^{26,34}$ Some studies were also at risk of selection bias; patients who received treatment were previously diagnosed with spondylosis or degenerative disc disease. These diagnoses might involve an increased number of spinal levels that could have an impact on outcomes that were analyzed. Ten of 13 studies among combined cage and posterior fixation studies, 6 of 12 studies among standalone fixation, and all 3 studies comparing the two techniques included deformity patients, and the heterogeneity of these patients should be acknowledged because they represent a more complex set of patients. Additionally, the method of and modality used in determining fusion was explained in some of the articles while others did not comment in much detail; any discrepancy in methodology and modality may have skewed the results. Moreover, we combined "cage subsidence" and "cage migration" into one outcome even though some experts have argued that these might be different clinical entities. However, given the small number of studies that analyzed these outcomes separately, the outcomes were grouped into one category. The main criteria for selection of studies for this review was complications, which is why we acknowledge that some studies that did not report complications were excluded. Given our findings of significantly higher subsidence and reoperations in standalone studies, we encourage future investigators to prioritize these outcomes. Finally, because only studies with available full-text were included, there might have been some selection bias. However, most of the studies included have been used in previous systematic reviews and the current study is intended to help the reviewers reevaluate the outcomes of the technique when categorized by the type of approach.

\section{Conclusions}

To the best of our knowledge, the current study is the first of its kind to compare the two approaches of trans- 
psoas fusion. The standalone procedure was found to be associated with a higher rate of reoperation as well as cage movement/subsidence in comparison to combined fusion.

\section{Acknowledgments}

We would like to thank Ms. Anne M. Farrell, LMS, for her help with the literature search and abstract collection.

\section{References}

1. Abbasi H, Abbasi A: Minimally invasive direct lateral interbody fusion (MIS-DLIF): proof of concept and perioperative results. Cureus 9:e979, 2017

2. Ahmadian A, Bach K, Bolinger B, Malham GM, Okonkwo DO, Kanter AS, et al: Stand-alone minimally invasive lateral lumbar interbody fusion: multicenter clinical outcomes. J Clin Neurosci 22:740-746, 2015

3. Alimi M, Lang G, Navarro-Ramirez R, Perrech M, Berlin C, Hofstetter CP, et al: The impact of cage dimensions, positioning, and side of approach in extreme lateral interbody fusion. Clin Spine Surg 31:E42-E49, 2018

4. Anand N, Baron EM, Thaiyananthan G, Khalsa K, Goldstein TB: Minimally invasive multilevel percutaneous correction and fusion for adult lumbar degenerative scoliosis: a technique and feasibility study. J Spinal Disord Tech 21:459467, 2008

5. Anand N, Rosemann R, Khalsa B, Baron EM: Mid-term to long-term clinical and functional outcomes of minimally invasive correction and fusion for adults with scoliosis. Neurosurg Focus 28(3):E6, 2010

6. Barbagallo GM, Albanese V, Raich AL, Dettori JR, Sherry N, Balsano M: Lumbar lateral interbody fusion (LLIF): comparative effectiveness and safety versus PLIF/TLIF and predictive factors affecting LLIF outcome. Evid Based Spine Care J 5:28-37, 2014

7. Bouthors C, Lachaniette CHF, Poignard A, Allain J: Results of LLIF with Avenue L cage in lumbar degenerative disease. Spine J 15 (3 Suppl):S55, 2015

8. Castellvi AE, Nienke TW, Marulanda GA, Murtagh RD, Santoni BG: Indirect decompression of lumbar stenosis with transpsoas interbody cages and percutaneous posterior instrumentation. Clin Orthop Relat Res 472:1784-1791, 2014

9. Centers for Disease Control and Prevention: Prevalence of disabilities and associated health conditions among adultsUnited States, 1999. JAMA 285:1571-1572, 2001

10. DerSimonian R, Laird N: Meta-analysis in clinical trials. Control Clin Trials 7:177-188, 1986

11. Drazin D, Kim TT, Johnson JP: Simultaneous lateral interbody fusion and posterior percutaneous instrumentation: early experience and technical considerations. BioMed Res Int 2015:458284, 2015

12. Essig DA, Cho W, Hughes AP, Huang RC, Sama AA, Girardi FP, et al: Risk factors for implant subsidence after standalone lateral lumbar interbody fusion. Spine J 14:S114, 2014

13. Goodrich JA, Volcan IJ (eds): Extreme Lateral Interbody Fusion (XLIF). St Louis: Quality Medical Publishing, 2013

14. Guyatt G, Oxman AD, Akl EA, Kunz R, Vist G, Brozek J, et al: GRADE guidelines: 1. Introduction-GRADE evidence profiles and summary of findings tables. J Clin Epidemiol 64:383-394, 2011

15. Heini PF, Teuscher R, Kleinschmidt: Anterior correction and fusion of the lumbar spine: The lateral approach with standalone cage interposition. Clinical outcome with a minimal one year follow up, in $\mathbf{7 3}$ Congres annuel de la Société Suisse d'Orthopédie et de Traumatologie, 2013 (Poster) (http://www.sgo13.organizers-congress.ch/downloads/ SGOT2013-Posters_130425.pdf) [Accessed August 14, 2018]

16. Higgins JPT, Green S (eds): Cochrane Handbook for
Systematic Reviews of Interventions, Version 5.1.0. London: The Cochrane Collaboration, 2011 (http://handbook. cochrane.org) [Accessed August 20, 2018]

17. Hoy D, Brooks P, Blyth F, Buchbinder R: The epidemiology of low back pain. Best Pract Res Clin Rheumatol 24:769781,2010

18. Isaacs RE, Hyde J, Goodrich JA, Rodgers WB, Phillips FM: A prospective, nonrandomized, multicenter evaluation of extreme lateral interbody fusion for the treatment of adult degenerative scoliosis: perioperative outcomes and complications. Spine (Phila Pa 1976) 35 (26 Suppl):S322-S330, 2010

19. Jin J, Ryu KS, Hur JW, Seong JH, Kim JS, Cho HJ: Comparative study of the difference of perioperative complication and radiologic results: MIS-DLIF (minimally invasive direct lateral lumbar interbody fusion) versus MIS-OLIF (minimally invasive oblique lateral lumbar interbody fusion). Clin Spine Surg 31:31-36, 2018

20. Joseph JR, Smith BW, La Marca F, Park P: Comparison of complication rates of minimally invasive transforaminal lumbar interbody fusion and lateral lumbar interbody fusion: a systematic review of the literature. Neurosurg Focus 39(4):E4, 2015

21. Kim CW, Siemionow K, Anderson DG, Phillips FM: The current state of minimally invasive spine surgery. Instr Course Lect 60:353-370, 2011

22. Kim JS, Lee HS, Shin DA, Kim KN, Yoon DH: Correction of coronal imbalance in degenerative lumbar spine disease following direct lateral interbody fusion (DLIF). Korean J Spine 9:176-180, 2012

23. Knight RQ, Schwaegler P, Hanscom D, Roh J: Direct lateral lumbar interbody fusion for degenerative conditions: early complication profile. J Spinal Disord Tech 22:34-37, 2009

24. Luo X, Pietrobon R, Sun SX, Liu GG, Hey L: Estimates and patterns of direct health care expenditures among individuals with back pain in the United States. Spine (Phila Pa 1976) 29:79-86, 2004

25. Malham GM, Ellis NJ, Parker RM, Blecher CM, White R, Goss B, et al: Maintenance of segmental lordosis and disk height in stand-alone and instrumented extreme lateral interbody fusion (XLIF). Clin Spine Surg 30:E90-E98, 2017

26. Marchi L, Abdala N, Oliveira L, Amaral R, Coutinho E, Pimenta L: Radiographic and clinical evaluation of cage subsidence after stand-alone lateral interbody fusion. J Neurosurg Spine 19:110-118, 2013

27. Marchi L, Abdala N, Oliveira L, Amaral R, Coutinho E, Pimenta L: Stand-alone lateral interbody fusion for the treatment of low-grade degenerative spondylolisthesis. Sci World J 2012:456346, 2012

28. McAfee PC, Shucosky E, Chotikul L, Salari B, Chen L, Jerrems D: Multilevel extreme lateral interbody fusion (XLIF) and osteotomies for 3-dimensional severe deformity: 25 consecutive cases. Int J Spine Surg 7:e8-e19, 2013

29. Mobbs RJ, Phan K, Malham G, Seex K, Rao PJ: Lumbar interbody fusion: techniques, indications and comparison of interbody fusion options including PLIF, TLIF, MI-TLIF, OLIF/ATP, LLIF and ALIF. J Spine Surg 1:2-18, 2015

30. Moher D, Liberati A, Tetzlaff J, Altman DG: Preferred reporting items for systematic reviews and meta-analyses: the PRISMA statement. Int J Surg 8:336-341, 2010

31. Nemani VM, Aichmair A, Taher F, Lebl DR, Hughes AP, Sama AA, et al: Rate of revision surgery after stand-alone lateral lumbar interbody fusion for lumbar spinal stenosis. Spine (Phila Pa 1976) 39:E326-E331, 2014

32. Oliveira L, Marchi L, Coutinho E, Abdala N, Pimenta L: The use of rh-bMP2 in standalone extreme lateral interbody fusion (XLIF): clinical and radiological results after 24 months follow-up. World Spinal Column J 1:19-25, 2010

33. Oliveira L, Marchi L, Coutinho E, Pimenta L: A radiographic assessment of the ability of the extreme lateral interbody fu- 
sion procedure to indirectly decompress the neural elements. Spine (Phila Pa 1976) 35 (26 Suppl):S331-S337, 2010

34. Oliveira L, Marchi L, Coutinho E, Pimenta L: The subsidence rate in XLIF osteoporotic patients in standalone procedures. Spine J 10:S51-S52, 2010

35. Ozgur BM, Agarwal V, Nail E, Pimenta L: Two-year clinical and radiographic success of minimally invasive lateral transpsoas approach for the treatment of degenerative lumbar conditions. SAS J 4:41-46, 2010

36. Ozgur BM, Aryan HE, Pimenta L, Taylor WR: Extreme lateral interbody fusion (XLIF): a novel surgical technique for anterior lumbar interbody fusion. Spine J 6:435-443, 2006

37. Pawar A, Hughes A, Girardi F, Sama A, Lebl D, Cammisa F: Lateral lumbar interbody fusion. Asian Spine J 9:978-983, 2015

38. Pimenta L, Marchi L, Oliveira L, Coutinho E, Amaral R: A prospective, randomized, controlled trial comparing radiographic and clinical outcomes between stand-alone lateral interbody lumbar fusion with either silicate calcium phosphate or rh-BMP2. J Neurol Surg A Cent Eur Neurosurg 74:343-350, 2013

39. Tempel ZJ, Gandhoke GS, Bolinger BD, Okonkwo DO, Kanter AS: Vertebral body fracture following stand-alone lateral lumbar interbody fusion (LLIF): report of two events out of 712 levels. Eur Spine J 24 (Suppl 3):409-413, 2015

40. Tessitore E, Molliqaj G, Schaller K, Gautschi OP: Extreme lateral interbody fusion (XLIF): A single-center clinical and radiological follow-up study of 20 patients. J Clin Neurosci 36:76-79, 2017

41. Tormenti MJ, Maserati MB, Bonfield CM, Okonkwo DO, Kanter AS: Complications and radiographic correction in adult scoliosis following combined transpsoas extreme lateral interbody fusion and posterior pedicle screw instrumentation. Neurosurg Focus 28(3):E7, 2010

42. Waddell B, Briski D, Qadir R, Godoy G, Houston AH, Rudman E, et al: Lateral lumbar interbody fusion for the correction of spondylolisthesis and adult degenerative scoliosis in high-risk patients: early radiographic results and complications. Ochsner J 14:23-31, 2014

43. Wang MY, Mummaneni PV: Minimally invasive surgery for thoracolumbar spinal deformity: initial clinical experience with clinical and radiographic outcomes. Neurosurg Focus 28(3):E9, 2010

44. Wells G, Shea B, O'Connell D, Peterson J, Welch V, Losos $M$, et al: Newcastle-Ottawa Scale (NOS) for assessing the quality of nonrandomised studies in meta-analyses. Ottawa: Ottawa Hospital, 2009 (http://www.ohri.ca/programs/ clinical_epidemiology/oxford.asp) [Accessed August 14, 2018]

45. Winder MJ, Gambhir S: Comparison of ALIF vs. XLIF for L4/5 interbody fusion: pros, cons, and literature review. J Spine Surg 2:2-8, 2016

46. Youssef JA, McAfee PC, Patty CA, Raley E, DeBauche S, Shucosky E, et al: Minimally invasive surgery: lateral approach interbody fusion: results and review. Spine (Phila Pa 1976) 35 (26 Suppl):S302-S311, 2010

\section{Disclosures}

The authors report no conflict of interest concerning the materials or methods used in this study or the findings specified in this paper.

\section{Author Contributions}

Conception and design: Alvi. Acquisition of data: Alvi, Alkhataybeh, Wahood. Analysis and interpretation of data: Alvi, Alkhataybeh, Wahood. Drafting the article: Alvi, Alkhataybeh, Wahood. Critically revising the article: Bydon, Alvi, Alkhataybeh, Kerezoudis, Goncalves, Murad. Reviewed submitted version of manuscript: Bydon, Alvi, Wahood, Kerezoudis, Goncalves, Murad. Statistical analysis: Bydon, Alvi, Wahood, Murad. Administrative/technical/material support: Bydon, Kerezoudis, Goncalves, Murad. Study supervision: Bydon.

\section{Supplemental Information}

Online-Only Content

Supplemental material is available with the online version of the article.

Supplemental Tables 1-3. https://thejns.org/doi/suppl/10.3171/ 2018.7.SPINE18385.

\section{Correspondence}

Mohamad Bydon: Mayo Clinic, Rochester, MN. bydon. mohamad@mayo.edu. 